\title{
Bridge dominated oxidation of a diruthenium 1,3-divinylphenylene complext+
}

\author{
Jörg Maurer, ${ }^{a}$ Rainer F. Winter, ${ }^{* a}$ Biprajit Sarkar, ${ }^{a}$ Jan Fiedler ${ }^{b}$ and Stanislav Záliš $b$ \\ a Institut für Anorganische Chemie der Universität Stuttgart, Pfaffenwaldring 55, D-70569 Stuttgart, \\ Germany \\ ${ }^{b}$ J. Heyrovský Institute of Physical Chemistry, Academy of Sciences of the Czech Republic, Dolejškova 3, \\ Prague, Czech Republic
}

\begin{abstract}
A divinylphenylene bridged diruthenium complex constitutes an ensemble of three coupled redox systems. Spectroelectrochemistry provides evidence that the oxidation processes are dominated by the organic bridge.
\end{abstract}

Complexes with two or more transition metal moieties bridged by a $\pi$-conjugated carbon-rich ligand have gained increasing importance, especially in the emerging field of molecular electronics. Here, such systems are exploited to study electronic interactions between the metal-based redox sites and to identify promising candidates for the assembly of larger-scale molecular wires. Polyynediyl and diethynylphenylene bridges have been well explored in this respect and found to be highly to moderately efficient coupling units. ${ }^{\prime}$ Oligoenediyl bridges equal oligoynediyl linkages of comparable lengths in their ability to convey charge and spin delocalization. ${ }^{2,3}$ No such investigations were, however, performed on related divinylphenylene bridged dinuclear complexes. ${ }^{4,5}$ The close resemblance of the divinylphenylene ligand to the repeat units of poly-phenylenevinylenes (PPVs), which constitute one of the most important classes of conducting polymers, ${ }^{6}$ provided a further incentive for undertaking such a study. Here we report our findings on the meta-bridged diruthenium complex $E, E$ $\left[\left\{\left(\mathrm{PPh}_{3}\right)_{2}(\mathrm{CO}) \mathrm{Cl}(4-\mathrm{EtOOCpy}) \mathrm{Ru}\right\}_{2}\left(\mu-1,3-\left(\mathrm{HC}=\mathrm{CH}-\mathrm{C}_{6} \mathrm{H}_{4}-\right.\right.\right.$ $\mathrm{CH}=\mathrm{CH})](1$, see Chart 1$)$.

1 was readily synthesized in $71 \%$ yield by double hydroruthenation of 1,3-diethynylbenzene with $\left[\mathrm{HRu}(\mathrm{CO}) \mathrm{Cl}\left(\mathrm{PPh}_{3}\right)_{3}\right]$ and treatment of the resulting $E, E-\left[\left\{\left(\mathrm{PPh}_{3}\right)_{2}(\mathrm{CO}) \mathrm{ClRu}\right\}_{2}(\mu-\right.$ $\left.1,3-\left(\mathrm{HC}=\mathrm{CH}-\mathrm{C}_{6} \mathrm{H}_{4}-\mathrm{CH}=\mathrm{CH}\right)\right]$ with a slight excess of ethylisonicotinate. $\S 4,7,8$ When 1 was subjected to voltammetric studies in $\mathrm{CH}_{2} \mathrm{Cl}_{2} / \mathrm{NBu}_{4} \mathrm{PF}_{6}$, two well separated and chemically reversible one-electron waves were detected at +0.235 and $+0.555 \mathrm{~V}$ as calibrated against the ferrocene/ferrocenium couple. The $\Delta E_{1 / 2}$ of $320 \mathrm{mV}$ signals, at first glance, a fairly strong metal-metal interaction, much stronger than that observed in comparable 1,3-diethynylbenzene bridged diiron complexes $\left(\Delta E_{1 / 2}=125\right.$ $\mathrm{mV}) .^{9}$ According to common belief, larger splittings of individual half-wave potentials of formally identical redox-sites are usually associated with a stronger electronic communication. ${ }^{10,11}$

In order to probe for the identity of the redox-sites and for charge and spin delocalization in the mixed-valent state we generated and spectroscopically studied the oxidized forms of 1 . IR spectroscopy

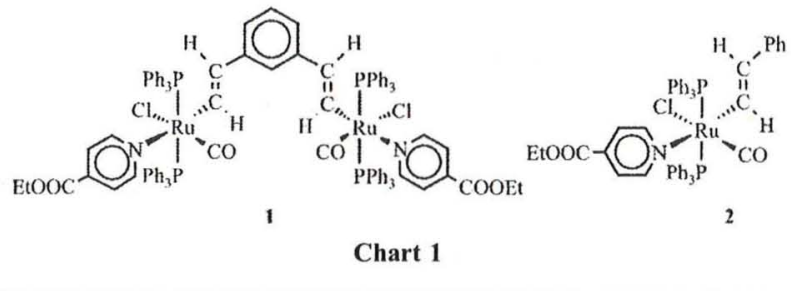

† Dedicated to Professor Helmut Werner on the occasion of his $70^{\text {th }}$ birthday.

\$ Electronic supplementary information (ESI) available: IR spectra of oxidation of 1 in $1,2-\mathrm{C}_{2} \mathrm{H}_{4} \mathrm{Cl}_{2} / \mathrm{NBu}_{4} \mathrm{PF}_{6}$ and $\mathrm{EPR}$ spectra of electrochemically generated $\mathbf{1}^{+}\left(\mathrm{CH}_{2} \mathrm{Cl}_{2} / \mathrm{TBAPF}_{6}\right)$. See http://www.rsc.org/suppdata/cc/b4/b405349d/ provides a particularly sensitive probe for intrinsic valence localization or delocalization. ${ }^{10}$ The isonicotinate complex 1 offers one carbonyl ligand at each ruthenium moiety and an IR active ester group at each pyridine ligand and is ideally suited for such investigations. During the first oxidation the single band at 1926 $\mathrm{cm}^{-1}$ of neutral 1 evolves into two separate bands at 1941 and 1963 $\mathrm{cm}^{-1}$, while the isonicotinate band shifts by just $3 \mathrm{~cm}^{-1}$ (Figure $\mathrm{S} 1$, Electronic Supplementary Information) \& Applying the usual criteria, such behaviour, along with the shift of both $\mathrm{CO}$ bands to higher energies, would be characteristic of a Class II system with moderately coupled but valence-trapped redox sites. ${ }^{10}$ During the second oxidation, the two $\mathrm{CO}$ absorptions of the monocation merge into one band which is now located at $1972 \mathrm{~cm}^{-1}$. This is accompanied by a further blue shift of the ester band by $4 \mathrm{~cm}^{-1}$. Remarkably, the total shift of the $\mathrm{CO}$ bands upon oxidation of 1 to its dication $1^{2+}$ amounts to just $46 \mathrm{~cm}^{-1}$. This is much less than the shifts of $100 \mathrm{~cm}^{-1}$ and more that usually accompany metal centered oxidations of carbonyl complexes. The analogous mononuclear styryl complex $E-\left[\left\{\left(\mathrm{PPh}_{3}\right)_{2}(\mathrm{CO}) \mathrm{Cl}(4-\mathrm{EtOOCpy}) \mathrm{Ru}\right\}(\mathrm{HC}=\mathrm{CH}-\right.$ $\mathrm{Ph})$ ] (2) behaves similarly.§ Oxidation at a potential sufficiently positive of its $E_{1 / 2}(+0.36 \mathrm{~V})$ shifts the $\mathrm{CO}$ band and the ester band to higher energies, by $40 \mathrm{~cm}^{-1}$ and $4 \mathrm{~cm}^{-1}$, respectively. The comparatively small magnitude of the $\mathrm{CO}$ shifts signals that a significant fraction of the positive charges in $\mathbf{1}^{+}, \mathbf{1}^{2+}$ and $2^{+}$is accommodated at the divinylphenylene ligand.

This finds support from UV-Vis-NIR spectroelectrochemistry. Oxidation of 1 to its radical cation gives rise to two structured bands near 17000 and $8000 \mathrm{~cm}^{-1}$ (Fig. 1). Both display progressions of 1420 and $1240 \mathrm{~cm}^{-1}$, respectively. Nearly identical spectra have been obtained for the radical cations of distyrylbenzenes or distyrylstyrenes and oxidatively doped PPV oligomers and polymers. ${ }^{12,13}$ This implies a significant bridge contribution to the singly occupied frontier levels (SOMOs) of $\mathbf{1}^{+}$and $\mathbf{2}^{+}$. This, in turn, can be probed by EPR spectroscopy. In fluid solution and at room temperature, electrochemically generated $\mathbf{1}^{+}$displays an intense, slightly broad isotropic spectrum. The g-value of 2.0201 is somewhat larger as is expected for a purely organic paramagnetic species. Successive cooling causes a further broadening of this signal until, starting at ca. $220 \mathrm{~K}$, a weak rhombic splitting prevails $\left(g_{x}=2.0326, g_{y}=2.0207, g_{z}=2.0107\right.$, Figure S2, ESI $) \neq$ The

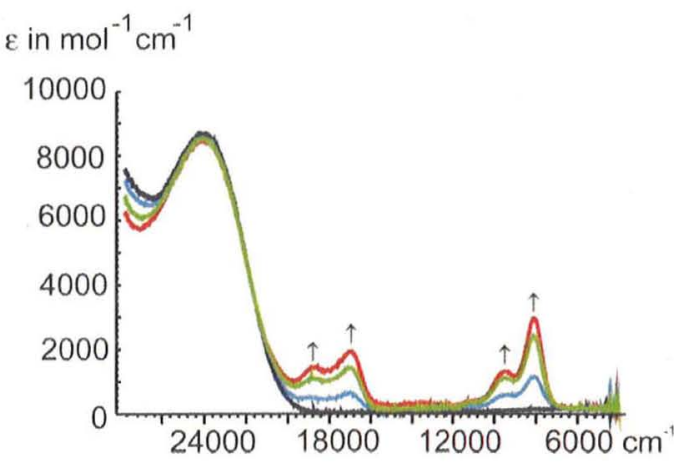

Fig. 1 Vis-NIR spectroscopic changes during the first (upper trace) and the second (lower trace) oxidation of 1 in $1,2-\mathrm{C}_{2} \mathrm{H}_{4} \mathrm{Cl}_{2} / \mathrm{NBu}_{4} \mathrm{PF}_{6}$. 

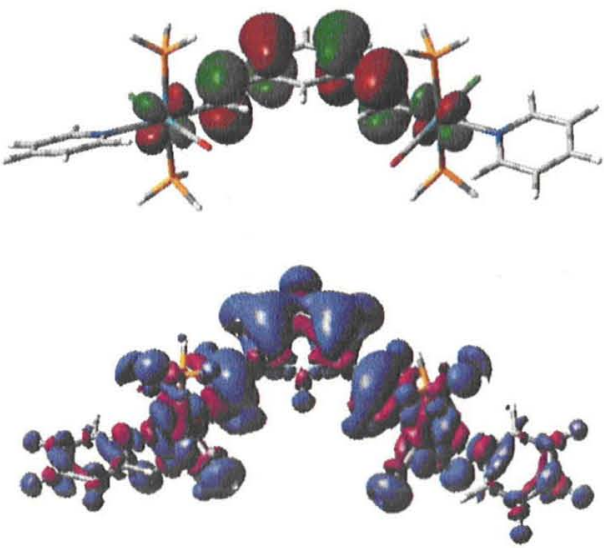

Fig. 2 Top: HOMO of $\mathbf{1}^{\prime}$. Bottom: changes of electron density distribution due to the oxidation of $\mathbf{1}^{\prime}$. Blue and violet colors correspond to a decrease and an increase in electron density, respectively.

slightly larger $g$-values obtained for $2^{+}\left(g_{\|}=2.0653, g_{\perp}=2.0382\right.$ in frozen solution) may point to a somewhat larger metal contribution as compared to $\mathbf{1}^{+}$. All this lets us conclude that $\mathbf{1}^{+}$and $2^{+}$are predominantly organic centered radicals with a minor, but clearly detectable, contribution of $\mathrm{Ru}$ d-functions to the spinbearing SOMO.

Further insight into the electronic structure of complex 1 was obtained by quantum chemical density functional theory (DFT) calculations on a somewhat simplified model $\mathbf{1}^{\prime}$ bearing $\mathrm{PH}_{3}$ instead of $\mathrm{PPh}_{3}$ ligands. Two nearly degenerate occupied levels in the frontier orbital region result from an antibonding interaction between the $\mathrm{Ru} \mathrm{d}$-orbitals and appropriate $\pi$-levels of the divinylphenylene bridge. Both are delocalized across the entire diruthenium-divinylphenylene moiety. Fig. 2 (top) depicts the highest occupied molecular orbital (HOMO). The contribution of the bridge $(81 \%)$ clearly dominates over that of the ruthenium atoms $(17 \%)$. The closely lying HOMO-1 has a similar composition and is formed by antisymmetrical combination of $\mathrm{Ru} 4 \mathrm{~d}_{X Z}$ orbitals. The pyridine ligands contribute less than $1 \%$ to these orbitals which explains the small IR shifts of the isonicotinate ester bands upon oxidation. Spin unrestricted DFT calculations on the radical cation $1^{\text {'+ }}$ confirm that the HOMO composition faithfully carries over to spin-densities. Moreover, the computational results on $\mathbf{1}^{\mathbf{\prime}}$ parallel our experimental findings in predicting two distinct $\mathrm{CO}$ absorptions and a slight rhombic splitting of the g-tensor in the monooxidized state. The calculated mean difference of $\mathrm{CO}$ stretching frequencies between $\mathbf{1}^{\prime}$ and $\mathbf{1}^{++}$of $25 \mathrm{~cm}^{-1}$ matches the experimentally observed shift. Calculating the charge differences induced by oxidation also indicates a significant loss of electron density from the bridge and only a smaller one from the $\mathrm{Ru}$ atoms (Fig. 2, bottom), again in perfect agreement with our experiments. The calculations give a symmetrical electron distribution in $\mathbf{1}^{+}$, and the calculated CO-band splitting of $13 \mathrm{~cm}^{-1}$ arises from a splitting of the symmetrical and antisymmetrical combinations of the two Ru$\mathrm{CO}$ stretches.

These results raise some points that are worthy of note. First of all, the divinylphenylene bridge is not an innocent ligand but, combined with the $\left\{\mathrm{Ru}(\mathrm{CO})\left(\mathrm{PPh}_{3}\right)_{2}(4\right.$-EtOOCpy) $\}$ moieties, forms an ensemble of three coupled redox systems. Secondly, the ligand not only participates in, but dominates, the anodic redox processes. This appears to be in sharp contrast to any of the dinuclear complexes bridged by some carbon-rich, conjugated spacer that have been investigated to date. Even though the oxidation mainly involves the divinylphenylene bridge, the oxidation potentials of 1 are substantially lower than those of alkylated oligovinylphenylenes. ${ }^{14}$ Moreover, the presence of the metal moieties endow the cations derived from $\mathbf{1}$ and $\mathbf{2}$ with stabilities that are usually not encountered in their purely organic counterparts. This would make oligomers of such complexes promising candidates as hole transporting components for e.g. optoelectronic applications.

S. Z. gratefully acknowledges financial support by COST (grant number OC D14.20) and the Grant Agency of the Czech Republic (grant No. 203/03/082).

\section{Notes and references}

§ Selected spectroscopic data: compound 1: IR KBr/cm-1 1920 (CO), 1725 (COOEt), $1586(\mathrm{C}=\mathrm{C}) ;{ }^{31} \mathrm{P}$ NMR $\left(101.256 \mathrm{MHz}, \mathrm{CDCl}_{3}\right), \delta 26.2(\mathrm{~s})$; ${ }^{1} \mathrm{H} \mathrm{NMR}\left(250 \mathrm{MHz}, \mathrm{CDCl}_{3}\right), \delta 8.70\left[4 \mathrm{H}, \mathrm{d}, \mathrm{py},{ }^{3} \mathrm{~J}_{\mathrm{H}-\mathrm{H}}=5.3 \mathrm{~Hz}\right], 8.58[2 \mathrm{H}$ $\left.\mathrm{dt}, \mathrm{C}=\mathrm{CH},{ }^{3} J_{\mathrm{H}-\mathrm{H}}=16.5 \mathrm{~Hz},{ }^{3} \mathrm{~J}_{\mathrm{P}-\mathrm{H}}=2.9 \mathrm{~Hz}\right], 7.40-7.58\left[20 \mathrm{H}, \mathrm{m}, \mathrm{PPh}_{3}\right]$, 7.05-7.30 [44H, m, $\mathrm{PPh}_{3}$, py], $6.90\left[1 \mathrm{H}, \mathrm{t}, \mathrm{H}^{5}\right.$ (bridge), $\left.{ }^{3} \mathrm{~J}_{\mathrm{H}-\mathrm{H}}=7.6 \mathrm{~Hz}\right]$, $6.54\left[2 \mathrm{H}, \mathrm{d}, \mathrm{H}^{4}, 6\right.$ (bridge), $\left.{ }^{3} \mathrm{~J}_{\mathrm{H}-\mathrm{H}}=7.6 \mathrm{~Hz}\right], 6.48\left[1 \mathrm{H}, \mathrm{s}, \mathrm{H}^{2}\right.$ (bridge), 5.83 $\left[2 \mathrm{H}, \mathrm{brd}, \mathrm{C}=\mathrm{CH},{ }^{3} \mathrm{~J}_{\mathrm{H}-\mathrm{H}}=16.5 \mathrm{~Hz}\right], 4.37\left[4 \mathrm{H}, \mathrm{q}, \mathrm{CH}_{2},{ }^{3} \mathrm{~J}_{\mathrm{H}-\mathrm{H}}=7.2 \mathrm{~Hz}\right], 1.39$ $\left[6 \mathrm{H}, \mathrm{t}, \mathrm{CH}_{3},{ }^{3} \mathrm{~J}_{\mathrm{H}-\mathrm{H}}=7.14 \mathrm{~Hz}\right]$; UV-VIS $\lambda_{\text {max }}$ in $\mathrm{nm}\left(\varepsilon_{\text {max }}\right)=410(6400)$, 290 (39000), 275 (40000). Compound 2: IR KBr/ $\mathrm{cm}^{-1} 1916$ (CO), 1727 (COOEt), $1594(\mathrm{C}=\mathrm{C})$; ${ }^{31} \mathrm{P}$ NMR $\left(101.256 \mathrm{MHz}, \mathrm{CDCl}_{3}\right) \delta 26.9(\mathrm{~s}) ;{ }^{\prime} \mathrm{H}$ NMR $\left(250 \mathrm{MHz}, 298 \mathrm{~K}, \mathrm{CDCl}_{3}\right), \delta 8.73\left[1 \mathrm{H}, \mathrm{dt}, \mathrm{C}=\mathrm{CH}, J_{\mathrm{H}-\mathrm{H}}=16.5 \mathrm{~Hz}\right.$, $\left.J_{\mathrm{P}-\mathrm{H}}=2.8 \mathrm{~Hz}\right], 8.66\left[2 \mathrm{H}, \mathrm{d}, \mathrm{py}, J_{\mathrm{H}-\mathrm{H}}=5.0 \mathrm{~Hz}\right], 6.84-7.52[37 \mathrm{H}, \mathrm{m}, \mathrm{Ph}$, py], $5.79\left[1 \mathrm{H}\right.$, br d, C=CH, $\left.J_{\mathrm{H}-\mathrm{H}}=16.5 \mathrm{~Hz}\right], 3.47\left[2 \mathrm{H}, \mathrm{q}, \mathrm{CH}_{2}, J_{\mathrm{H}-\mathrm{H}}=7.0\right.$ $\mathrm{Hz}], 1.20\left[3 \mathrm{H}, \mathrm{t}, \mathrm{CH}_{3}, J_{\mathrm{II}} \mathrm{H}=7.0 \mathrm{~Hz}\right]$; UV-VIS $\lambda_{\max }$ in $\mathrm{nm}\left(\varepsilon_{\max }\right)=400$ (3700), 285m (26500), 279 (26500).

The ground-state electronic structures were calculated by density functional theory (DFT) methods using the Gaussian 03 program package. The quasirelativistic effective core pseudopotentials and the corresponding optimized set of basis functions for Ru and $6-31 \mathrm{G}^{*}$ polarized double- $\zeta$ basis sets for remaining atoms were employed together with the B3LYP functional. For details see http://www.gaussian.com/.

1 F. Paul and C. Lapinte, Coord. Chem. Rev., 1998, 178-180, 431

2 M.-C. Chung, X. Gu, B. A. Etzenhouser, A. M. Spuches, P. T. Rye, S. K. Seetharaman, D. J. Rose, J. Zubieta and M. B. Sponsler, Organometallics, 2003, 22, 3485.

3 M. B. Sponsler, Organometallics, 1995, 14, 1920

4 A. Santos, J. López, J. Montoya, P. Noheda, A. Romero and A. M. Echavarren, Organometallics, 1994, 13, 3605

5 Interesting examples of oligo-phenylenevinylenes as conducting bridges between a modified TTF donor and a $\mathrm{C}_{60}$ acceptor have just been published. F. Giacalone, J. L. Segura, N. Martin and D. M. Guldi, J. Am. Chem. Soc., 2004, 126, 5340

6 A. J. Heeger, Angew. Chem., Int. Ed., 2001, 40, 2591.

7 M. R. Torres, A. Vegas and A. Santos, J. Organomet. Chem., 1986, 309, 169.

8 B. Gómez-Lor, A. Santos, M. Ruiz and A. M. Echavarren, Eur. J. Inorg. Chem., 2001, 2305.

9 T. Weyland, K. Costuas, L. Toupet, J.-F. Halet and C. Lapinte, Organometallics, 2000, 19, 4228.

10 C. G. Atwood and W. E. Geiger, J. Am. Chem. Soc., 2000, 122, 5477.

11 F. Barrière, N. Camire, W. E. Geiger, U. T. Mueller-Westerhoff and R. Sanders, J. Am. Chem. Soc., 2002, 124, 7262.

12 H. Bässler, M. Deußen, S. Heun, U. Lemmer and R. F. Mahrt, Z. Phys, Chem., 1994, 184, 233.

13 A. Sakamoto, Y. Furukawa and M. Tasumi, J. Phys. Chem., 1994, 98, 4635 .

14 1,1-Bis(4-tert-butylstyryl)benzene, for example, is oxidized at $+0.92 \mathrm{~V}$ and $c a .+1.28 \mathrm{~V}$ vs. the ferrocene/ferrocenium couple; see M. S. Liu, X. Jiang, S. Liu, P. Herguth and A. K.-Y. Jen, Macromolecules, 2002, 35, 3532 . 